\title{
INTEGRATING THE PRINCIPLES OF GREEN MARKETING BY USING BIG DATA. GOOD PRACTIGES
}

\author{
Mihai Andronie ${ }^{1 *}$, Daniel Adrian Gârdan ${ }^{2}$, Ionel Dumitru ${ }^{3}$, \\ Iuliana Petronela Gârdan ${ }^{4}$, Irina Elena Andronie ${ }^{5}$ and Cristian Uță ${ }^{6}$ \\ ${ }^{1224) 556)}$ Spiru Haret University, Bucharest, Romania \\ 3) The Bucharest University of Economic Studies, Romania
}

\section{Please cite this article as:}

Andronie, M., Gârdan, D.A., Dumitru, I., Gârdan, I.P., Andronie, I.E. and Uță, C., 2019. Integrating the Principles of Green Marketing by Using Big Data. Good Practices. Amfiteatru Economic, 21(50), pp. 258-269.

DOI: $10.24818 / \mathrm{EA} / 2019 / 50 / 258$

\section{Article History}

Received: 20 September 2018

Revised: 16 November 2018

Accepted: 20 December 2018

\begin{abstract}
Implementing the principles of green marketing started since the 70's, once the social and societal marketing concepts were defined. The challenges brought around by globalization and the excessive pollution of the environment, that contemporary companies had to face, requested the implementation of new business models and rethinking the strategic approach of their activities. They have generated the rationale and sustainable use of resources, the reduction of waste generated by production processes, the consumers' education towards developing a mentality that is favouring responsible consumption, the preservation and respect of the environment and adopting some specific measures intended to contribute to the preservation of nature by all stakeholders in the value chains.

Good practices regarding the implementation of green marketing strategies provide a series of principles, action guidelines useful to any organisation willing to answer the challenges of the current century. In this respect, it is imperative to develop a marketing mix adapted to the requests of bioeconomy. In this context, the current paper proposes to present bioeconomy tendencies and good practices in the context of large data volumes that organisations have to manage more and more often.
\end{abstract}

Key-words: green marketing; big data; sustainability; optimizing the marketing processes.

JEL classification: I21, Q00, M00, Q01, Q56

*Corresponding author, Mihai Andronie - mihai.andronie@gmail.com 


\section{Introduction}

The recent major changes regarding the accelerated demographic, technological and industrial development have enhanced the effects of human activity on the environment. They occurred at a global scale, recently entering the category of major threats faced by the planet: climate change, the consistent reduction of the ozone layer, the stressed degradation of the natural environment, the increase of pollution, the reduction of resources, the growth in terms of consumption of raw materials, the increase in products that are dumped etc. (Costanza et al., 2015; Dabija et al., 2018).

The identification of certain solutions, measures and strategies for managing and solving efficiently the global challenges derived from the necessity to preserve and protect the natural environment became a key priority for international bodies and regional authorities, both for governments and organisations. They are making more intense and conjugate efforts for counterbalancing the negative effects of all threats to the planet. In a holistic approach, the UN defined since 1987 the sustainable development concept (WCED, 1987), which approaches the principles and contribution of any type of organization in protecting nature and in identifying some preventive solutions allowing to anticipate problems, risks and accidents regarding intense resource consumption, polluting the environment and protecting it.

The implementation of the sustainable development principles by organisations must be carried out for all activities and processes adopted by them: supply, production, information, research, development, distribution, maintaining contact with suppliers and customers etc (Pistol and Țoniș, 2017). An important concern is directed towards the human capital and its development, seen as a strategic resource in terms of a sustainable growth of economic agents (Iatagan, 2015).

The substantial change in the production processes in order to diminish resource and raw material consumption, namely the development of environmental-friendly benefits, including the current technological developments, as well as intellectual capital, represent the basis for developing and implementing sustainable marketing strategies (Dabija and Pop, 2013; Dabija and Băbut,, 2013). The design of the new ecologic and/ or environmental-friendly benefits, based on the sustainable development processes enter more and more in the task of the marketing area which had a substantial contribution in developing the product concept. The integration of the defining features and elements of sustainability in the marketing thinking allowed the development of a market for "green", sustainable products. At the same time with the development of a market for ecologic benefits, organisations passed also to generate a favourable mentality among consumers, highlighting their health benefits, as well as the contribution of individuals for preserving the environment and for diminishing the consumption of resources (Pop and Dabija, 2013; Dabija et al., 2018).

Currently, any organisation aiming the improvement of market positioning, must apply consistently the sustainable development principles within their market approach strategy, especially the ones regarding environment protection, thus developing and strengthening competitive advantages. The successful implementation of such an approach is, of course, a real challenge for marketers, the success being conditioned by the type of business managed on the targeted market and its dynamics, the strength of the competitors, and the ability of the organization to adapt to a turbulent environment. 


\section{The evolution of the green marketing concept}

A first reference to the ecologic or "green" marketing dates back to the year 1976, when it was considered to include all the activities of an organisation that lead to promoting the cause of environment issues and to providing some viable solutions for counteract, prevent or eliminate them. From this point of view, marketing outstands by its social component used for implementing environmental governance (Dangelico and Vocalelli, 2017; Dabija et al., 2017). Over time, the concept got crystallised and enriched, later on being defined as the process for planning, implementing and controlling the development, distribution and for promoting the benefits of organisations, establishing their prices, so as to integrate, as a synergy, customers needs satisfaction, the fulfilment of the goals of the organisations, i.e. ensuring the compatibility of the processes with the existing ecosystems (Fuller, 1999).

The literature dedicated to green marketing and its forms of manifestation ("green" communication, ecologic consumers, environmental friendly benefits, a mentality favouring ecologic products, environmental governance, recycling behaviour etc.) shows the fact that it must be able, at the same time, to develop high quality benefits, environmental friendly and according to the expectancies of the consumers (Peattie, 2001; Ottman et al., 2006; Radnovic et al., 2012; Dabija and Pop, 2013; Kumar et al., 2013; Pop and Dabija, 2013; Ratcliffe and Coutler, 2015; Papadas et al., 2017). In implementing the green marketing principles, organisations focus more and more frequently on the clean technology development, oriented towards reducing the consumption of resources and on protecting the environment. They must be used so that they might generate competitive advantages (Peattie, 2001).

In the knowledge society, green marketing is facing new and diverse challenges derived from the technological evolution and the need of the organisations to identify viable strategies, able to keep generating a competitive advantage by including the results of technological progress and innovations in all their production processes.

Intelligent growth means integrating innovations in the economy, improving education and the performance of research and promoting a viable knowledge transfer (Ciucă et al., 2016).

In fact, nowadays, green marketing is responsible for fostering economic processes as a result of facilitating access for various information, issued by the competition, customers, namely the market environment. Based on the information obtained via the sustainable, ecologic strategies for processing the markets, organisations must take specific measures meant to stop the deterioration of the environment, improve the quality of life for customers, but also to sustainably preserved resources (Papadas et al., 2017). The ability of green marketing to contribute to the generation of safe benefits along with the amelioration respectively improvement of intra-firm processes by reducing their impact on the environment is somehow guaranteed by the intrinsic essence of the concept and its social dimension. Socially speaking, green marketing aims at changing the behaviour of economic agents in order to make the entire human activity compatible with the existing ecosystems. Therewith, frequent changes in the market environment favour the development and implementation of new marketing strategies to help achieve sustainable eco-innovation. Consequently, green marketing becomes a fundamental component in the successful implementation of the marketing mix and the strategies and policies required for environmental governance.

The recent developments of the market environment favour more intensely the identification of viable solutions for including IT\&C with green marketing and the strategies developed based on its principles. IT\&C lead to the appearance of big data collections, whose proper analysis and interpretation can contribute to improving the organization's activities, better 
understanding the customers and competitors, and especially to quickly adapt to any change of the internal and external parameters depending on which strategies are usually developed (Pistol et al., 2016).

\section{The advantages of implementing the green marketing specific principles}

The organisations implementing sustainable strategies sent thereof a strong message to the stakeholders regarding the capacity to acknowledge the risks and challenges of the business environment, but also to adapt to the changes of the market environment. Basically, these organisations, by their activities and the implemented strategies, are aligned to certain social needs, transposing "green" marketing in all their internal processes (Lash and Wellington, 2011). The enforcement of the "green" marketing principles is done at the level of all the components of the mix, developing competitive advantages by differentiating the benefits and by the targeted organisational culture (Kotler, 2011).

The potential of green marketing to provide an essential contribution, namely added value to developing sustainable strategies, is obvious, recent studies (Fuentes, 2015) showing that most of the times its effective implementation can prove to be a real challenge for marketers because consumers do not always perceive the virtues and the relevance of ecologic benefits or of the green marketing-based sustainable strategies to them. For instance, the most frequently sold products apart from ecologic food, gaining more and more importance in Romania, too (Pop and Dabija, 2013), are represented by the energy saving systems, i.e. nonfood "green" products (Makower, 2011), indicating the need that for the future, marketers should explain better such phenomena.

By consuming ecologic products, consumers can obtain some obvious benefits, such as: a favourable price/ added value ratio; health and safety; performance; status and symbolism; comfort and utility. Marketers must make constant efforts for promoting and educating them (e.g. price reductions) and in highlighting the intrinsic benefits from consuming them (Ottman et al., 2006; Radnovic, 2012).

Applying green marketing in organisations pursuing a sustainable strategy requires following some specific principles constantly, among which the ones of circular economy (a raw material turns into a consumption good, which, after being used by the customer, becomes recyclable waste); ensuring the ecologic balance of the marketing strategy; preventing pollution and the contribution of the organisation to regenerating nature, i.e. designing the business strategies so that they might allow the protection of the ecosystems (Alexandru et al, 2015).

The current evolution of the Romanian economy justifies the existence of more clear concerns about the application of green marketing within companies. They start to be aware of the importance of communicating such concerns also due to the impact they can have on customers, investors and other stakeholders. The sustainability culture allows organisations to obtain better results regarding the efficient use of resources, along with obtaining better customer satisfaction by resorting to the principles of sustainability (Mauri and Baicu, 2009). This approach creates a proper framework for applying green marketing, thus organisations managing to be more successful in the business environment. In the context of analysing some good practices on applying green marketing it is important to highlight the danger of the marketing myopia phenomenon.

Marketing myopia, postulated by Levitt (1975), which aims to explain a narrow business vision implemented by organizations, is gaining importance in the case of companies that do not 
manage to understand the relevance of resorting to a sustainable business strategy and to ecologic, sustainable benefits. The market success of "green" products needs developing a favourable mentality among customers, their appropriate positioning on the market by highlighting the benefits of these products for maintaining or even improving the health of the consumers, as well as promoting them intensely (Pop and Dabija, 2013; Dabija et al., 2018).

The principles that ensure companies to avoid marketing myopia in implementing green marketing take into account at least, the following elements (Ottman et al., 2006):

- conceiving and developing ecologic benefits with superior features, respectively improved versus the conventional versions existing on the market; (compared to the conventional variants existing on the market);

- promoting and presenting the features and the added value of the ecologic benefits among the representative market segments and adapting them to the individuals' needs, expectancies and preferences;

- educating consumers by means of appropriate marketing messages and by highlighting the intrinsic advantages of the ecologic benefits, such as "no pesticides"; "healthier"; "efficient"; "supporting financial savings"; "natural"; "adapted to human consumption"; "protecting nature" etc.;

- highlighting the fact that ecologic benefits are the most suitable "solutions" for "green" consumption, being aware of the need to protect the environment;

- creating some interesting, inciting and educating webpages about the consumers' expected value of the ecologic benefits;

- obtaining "green" recommendations and certifications representative for the ecologic benefits, issued by acknowledged authorities in the field and educating consumers to search for and recognize these marks.

Large companies in the market, which got involved in developing green marketing, use a series of successful practices regarding the creation of a quality commitment from the consumers. These take into account different actions developed in a structured, coherent manner, as shown in figure no. 1 (Ratclife and Coutler, 2015).

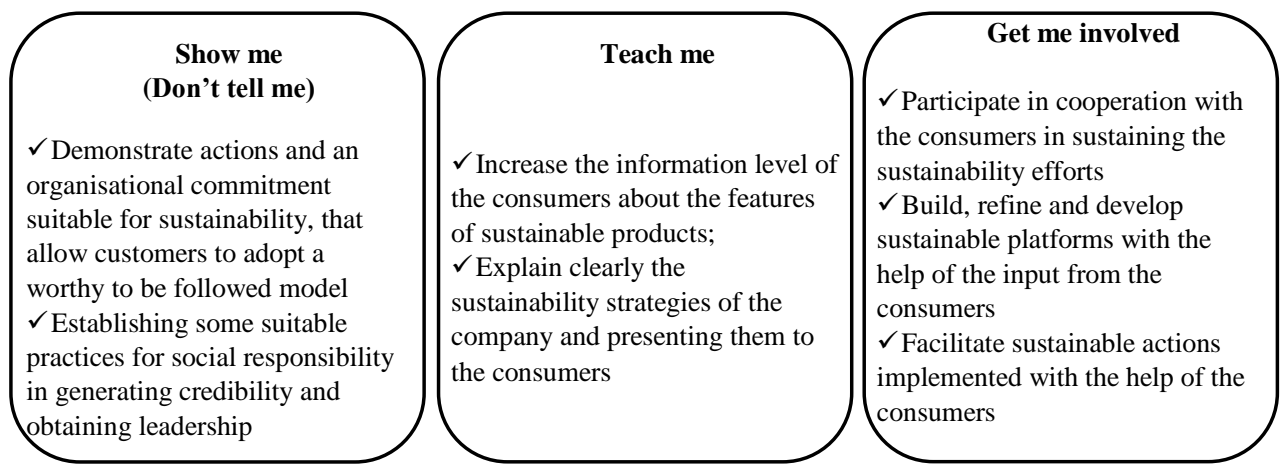

Figure no. 1: Good practices strategies for involving consumers in ensuring the sustainability of organisations

Source: Ratclife and Coutler, 2015, p.3 
The implementation of green marketing in organisation can be done on three decisional levels: green marketing strategic orientation, tactical, respectively the internal one (Papadas et al., 2017). The green marketing strategic orientation refers to the long-term management actions and policies, which concentrate mainly on implementing an appropriate environment governance. The tactical green marketing orientation implies short-term actions which transform the classical marketing mix into a specific ecologic strategy and benefits specific one. The internal green marketing orientation implies disseminating the environment values throughout the organisation in order to incorporate a large ecologic corporate culture.

\section{Using "big data" collections in the green marketing strategy}

A successful application of the "green" marketing principles in the activity of the organisations aims at incorporating the newest and most cutting edge marketing information and data into the implemented strategies. "Big data" present on the market represent a subject largely debated during the last years, resulting from the unprecedented progress in IT\&C. Even if, intensely debated in the literature, most organisation managers do not always understand the relevance of this concept and, moreover, they use these data only in a limited way in marketing decision-making, in drafting the benefits strategies, namely in properly understanding the signals transmitted by the competition and customers (Verhoef et al., 2016; Power, 2014). The benefits of using these data properly are tremendous, contributing to gain competitive advantages.

Through the incorporated technological progress, big data trigger both the utopic and the dystopian rhetoric. Big data are considered a real tool for approaching different social problems, providing the potential of some new perspectives in wide fields: research on global scourge, terrorism and climate change. On the other hand, they are considered as a potential threat to individual privacy, reducing or even restraining civil freedom and increasing the relevance of the control exerted on the freedom of speech. The possible interpretation of these data show varied and subtle changes for the on-going activities (Sivarajah et al., 2017). Big data represent huge volumes of information which are difficult to be managed with the usual processing tools and techniques (Hampton et al., 2013). Such batches of data require a special hardware and software infrastructure for identifying, acquiring, managing and processing them in an acceptable timeframe (Chen et al., 2014; Şerban et al., 2015). They cannot be always stored for later, being analysed, processed in real time, allowing companies to adapt on the go to the environment changes and requirements, namely the preferences of the customers (McAfee and Brynjolfsson, 2012).

Often, big data are composed of different types of information which are complex and heterogeneous, structured, semi-structured and even unstructured. Among them, there are the tabular and relational databases (structured accordingly), data deposits, text data, webpages, and images in various formats, audio, video etc. (Wu et al., 2014; Ştefan, 2016). Big data can contain duplicate information, which are not always exact or even contradictory. Big data can have more sources, one of the most known being social networks, images, sensor networks and the Internet as a whole. Currently, there are more data uploaded on the internet every second than they were stored across the entire internet 25 years ago (McAfee and Brynjolfsson, 2012). 
The features that differentiate big data from the common ones are explained via the $4 \mathrm{~V}$ model (velocity, volume, veracity, variety) (Grover et al., 2018):

- velocity: represents the essential feature contributing to obtaining and generating them, but also for their availability period;

- volume: the massive data quantity represents information which can hardly be managed with traditional processing tools, the important data requiring their collection, storage and processing them with special hardware-software infrastructure;

- veracity: refers to the problem generated by their ownership, credibility and accuracy; that is why, if the common analysis tools are used for big data, the results might be wrong;

- variety: refers to the multitude of data types that can be met.

To those 4Vs, a fifth can be added: ,value”. Big data contain valuable models and knowledge, which can be extracted using some appropriate exploitation techniques, providing opportunities to the organisations that can access and exploit them efficiently (Deepak and Sultana, 2015; Al-Fuqaha et al., 2015).

The potential offered by big data in following a sustainable business strategy represent a controversial issue in the literature, using a system able to manage big data requires the use of more resources which generate challenges for the organisations in obtaining a certain efficiency of the sustainability of their activity. Managers who are managing their organisations according to the green marketing principles must identify the best ways to be followed based on the decisions made. However, their substantiation can become problematic or even questionable in this context, the major challenge depending on how large data volumes are being approached and the possibilities for extracting useful and relevant knowledge. In a constantly changing business environment, organisations which incorporate the green marketing principles in their business philosophy must understand the fact that the data volume to be processed is growing exponentially. It requires creating specialised IT department, able to process large information volumes and to transform them into relevant business information, able to generate valuable ideas for the company. The expenditure for research-development activities addressing ecologic technologies have became a priority in the economic simulation packages used by them (Zaman and Gherasim, 2010).

Using big data in correlation with the analysis of the environment, namely according to the green marketing philosophy is still at an early stage. The available data regarding the environmental activities of the organisations usually can be acquired at high costs, by remote observations and with the help of sensor networks (Jones et al., 2006). However, there are rather small companies in terms of their activity impact, that have their own data collections regarding the environment, and which can have the potential to be integrated as large data batches (Hampton et al., 2013). Unfortunately, these organisations are rarely disposed to provide these data to others in order to use in making relevant decisions at sector level. Specialists estimate that many of the available data on the environment are lost and that cooperation projects are abandoned even before they are starting (Baumann et al., 2016; Song et al., 2018).

Big data, along with other innovative technologies are known as mechanisms created by the companies to reduce their negative impact on the environment, since they lay the grounds for developing eco-innovation strategies. In this context, green marketing is considered as one of the four dimensions of ecologic innovation, along with the ecologic product development, the 
integration of the business model and sustainable consumption (Kuo and Smith, 2018). Over time more tendencies were discovered that imply using large data sets for the marketing decisions and strategies in organisations (Roberts et al., 2014). Using them in enterprises can have a positive effect on preserving and protecting the environment $(\mathrm{Wu}, 2017)$. Using big data and predictive analysis techniques has a significant impact on the social and environmental performance of the companies. In a research on 205 companies in India, the authors highlighted the potential of using big data and predictive analysis in growing the sustainability degree of the activity of the companies in the new supply chains (Dubey et al., 2017).

A special field proving the capacity of big data to have a major input in implementing the green marketing principles is represented by sustainable production. This assumes, according to the US Department of Commerce: "creating manufactured products using processes that minimize the negative impact on the environment, preserves energy and natural resources and are safe for the employees, communities and consumers, being also healthy economically speaking" (International Trade Administration, 2007). Integration of environmental requirements across the product lifecycle requires a new way of thinking and new decisional instruments, so that, in fact sustainable production will suppose an ecologic product design, ecologic provisioning, involvement of ecologic production processes and ecologic technologies - in other words applying green marketing at a large scale. In order to implement sustainable production and to have improved performance, each economic agent must excel in the three areas specific to the performance and sustainability of the activity: economic, environmental and social.

This requires using large data volumes, namely acquiring, storing and using big data for decision-making related to the supply chain and the objectives of the strategy (Dubey et al., 2016). Sustainable production implies integrating successfully more elements, as shown in figure no. 2 .

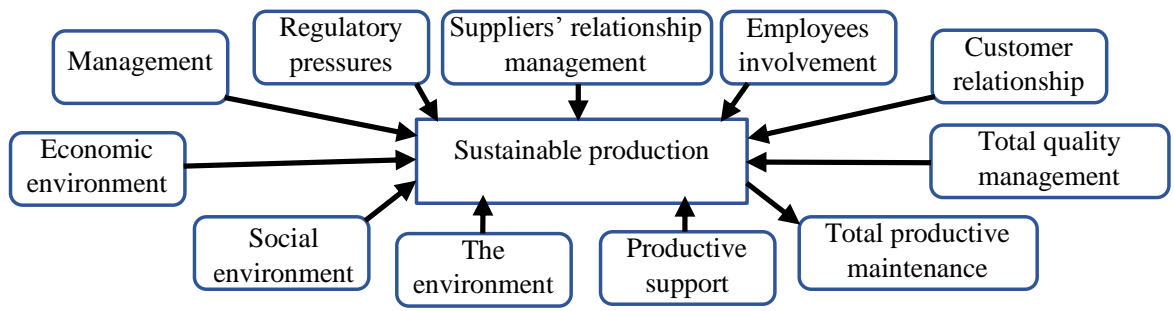

Figure no. 2: Elements of the reference framework for sustainable production Source: apud Dubey et al., 2016, p.636.

In order for the real potential of big data to be highlighted, there is a need for support and commitment at the level of the top management.

Only in this context decision makers can acquire adequate analytical capabilities for big data management. Organizational culture characterized by flexibility and adaptability is also essential to ensure the conditions of big data use and integration into a business strategy specific to green marketing. Future trends indicate the appetite of organizations that are developing green marketing implementation for more and more creative use of tools such as big data, tools that currently offer possibilities yet only inherent to manage an appropriate flow of decision-making in order to increase sustainability. 


\section{Conclusions}

The principles of green marketing aim at developing and promoting sustainable consumption irrespective of the type of the benefits considered. Individuals who consume sustainably modify substantially their specific life style and behaviours, the way of being informed and processing information, as well as the way to transfer to third parties their consumption experiences, values, beliefs, attitudes, perceptions and motivations. Sustainable marketing will control the entire value chain addressed to the consumer, promoting business models which eliminate waste and optimize resources transformation. Through its implementation, economic organisations strengthen their institutional image in capitalizing on some attributes that resonate with social responsibility and economic sustainability. Companies adopting the green marketing-specific principles become more credible also in dealing with the public entities in charge with the implementation of the environmental policies, NGOs or representatives of different communities active in managing global environmental problems or in promoting a sustainable resource consumption.

The companies that are willing to have competitive advantages based on increased sustainability related to the environment have greater chances of succeeding in differentiating from competition. As the market evolves and the consumer develops an optic according to such values, companies will have to adapt and to incorporate in their own business strategies the sustainable model according to the green marketing principles. Good practices in this field are closely correlated with the widespread use of new technologies such as big data. They suppose changing the managerial optic of the enterprises, integrating the sustainability principles in the marketing mix, educating consumers towards a healthy lifestyle and a stronger involvement in communicating on social channels the newly adopted values. Social responsibility, anchored in the important realities for the Romanian consumer, will become an excellence standard which can ensure for each economic agent an appropriate positioning on the market and the premises for an optimal future evolution.

\section{References}

Alexandru Vlad, C., Ungureanu, G. and Militaru, M., 2015. Intangible Assets as a Source of Competitiveness. Ovidius University Annals, Economic Sciences Series, 15(1), pp.423426.

Al-Fuqaha, A., Guizani, M., Mohammadi, M., Aledhari, M. and Ayyash, M., 2015. Internet of things: A survey on enabling technologies, protocols, and applications. IEEE Communications Surveys \& Tutorials, 17(4), pp.2347-2376.

Baumann, P., Mazzetti, P., Ungar, J., Barbera, R., Barboni, D., Beccati, A., Bigagli, L., Boldrini, E., Bruno, R., Calanducci, A. and Campalani, P., 2016. Big data analytics for earth sciences: the EarthServer approach. International Journal of Digital Earth, 9(1), pp.3-29.

Ciucă, V., Pașnicu, D., Tudose, G. and Pașnicu, M.R., 2016, Correlations between Expenditure and Employees in R\&D Activity by Performance Sectors from Romania. Romanian Statistical Review, iss. 1, pp. 42-51.

Chen, M., Mao, S. and Liu, Y., 2014. Big data: A survey. Mobile Networks and Applications, 19(2), pp.171-209.

Costanza, R., Daly, H., Cumberland, J.H., Goodland, R., Norgaard, R.B., Kubiszewski, I. and Franco, C., 2014. An Introduction to Ecological Economics. S.1: CRC Press. 
Dabija, D.C. and Băbuţ, R., 2013. An Approach to Sustainable Development from Tourist's Perspective. Empirical Evidence in Romania. Amfiteatru Economic, 15(Special Issue 7), pp.617-633.

Dabija, D.C. and Pop, C.M., 2013. Green marketing - Factor of Competitiveness in Retailing. Environmental Engineering and Management Journal, 12(2), pp.393-400.

Dabija, D.C., Cheben, J. and Lancaric, D., 2017. Cross-cultural investigation of consumers' generations attitudes towards purchase of environmentally friendly products in apparel retail. Studies in Business and Economics, 12(3), pp.27-42.

Dabija, D.C., Postelnicu, C. and Dinu, V., 2018. Cross-Generational Investigation of Ethics and Sustainability. Insights from Romanian Retailing. In: S.O. Idowu, C. Sitnikov, D. Simion and C. Bocean, eds. 2018. Current Issues in Corporate Social Responsibility. An International Consideration. Cham: Springer International Publishing, pp.141-163.

Dangelico, R.M. and Vocalelli, D., 2017. "Green Marketing": an analysis of definitions, strategy steps, and tools through a systematic review of the literature. Journal of Cleaner Production, 165, pp.1263-1279.

Dinu, V., 2008. The ethical dimension of business. Amfiteatru Economic, 10(23) pp.7-8.

Dubey, R., Gunasekaran, A., Childe, S.J., Papadopoulos, T., Luo, Z., Wamba, S.F. and Roubaud, D., 2017. Can big data and predictive analytics improve social and environmental sustainability?. Technological Forecasting and Social Change, http://dx.doi.org/10.1016/j.techfore.2017.06.020

Dubey, R., Gunasekaran, A., Childe, S.J., Wamba, S.F. and Papadopoulos, T., 2016. The impact of big data on world-class sustainable manufacturing. The International Journal of Advanced Manufacturing Technology, 84(1-4), pp.631-645.

Fuller, D.A., 1999. Sustainable marketing: Managerial-ecological issues. S.1: Sage Publications.

Grover V., Chiang H.L.R., Liang T.P. and Zhang D., 2018. Creating Strategic Business Value from Big Data Analytics: A Research Framework. Journal of Management Information Systems, 35(2), pp.388-423.

Hampton, S.E., Strasser, C.A., Tewksbury, J.J., Gram, W.K., Budden, A.E., Batcheller, A.L., Duke, C.S. and Porter, J.H., 2013. Big data and the future of ecology. Frontiers in Ecology and the Environment, 11(3), pp.156-162.

Iatagan, M., 2015. The Human Capital - Key Factor for Getting Over the Economic Crisis, Quality-Access to Success, 16.

Ilic, D., Stankovic, J. and Ilic, S., 2013. Marketing sustainable retail development. Journal of Economic Development, Environment and People, 2(2), pp.51-61.

International Trade Administration, 2007. How Does Commerce Define Sustainable Manufacturing? [online] U.S. Department of Commerce. Available at: <www.trade.gov/competitiveness/sustainablemanufacturing/how_doc_defines_SM.asp> [Accessed 10 September 2018].

Jones, M.B., Schildhauer, M.P., Reichman, O.J. and Bowers, S., 2006. The new bioinformatics: integrating ecological data from the gene to the biosphere. Annual Review of Ecology Evolution and Systematics, 37, pp.519-544.

Kumar, V., Rahman, Z. and Kazmi, A.A., 2013. Sustainability marketing strategy: an analysis of recent literature. Global Business Review, 14, pp.601-625. 
Kuo, T.C. and Smith, S., 2018. A systematic review of technologies involving eco-innovation for enterprises moving towards sustainability. Journal of Cleaner Production, 192, pp. 207-220.

Levitt, T., 1975. Marketing myopia. Harvard Business Review, 53(5), pp.26-183.

Makower, J., 2011. Green Marketing Is Over. Let's Move On. Green Biz, [online] Available at: <www.greenbiz.com/blog/2011/05/16/green-marketing-over-lets-move> [Accessed 10 September 2018].

Mauri, A. and Baicu, C., 2009. The current financial crisis and lessons which can be gained. Annals of Spiru Haret University, Economic Series, 1(1), pp.11-20.

McAfee, A. and Brynjolfsson, E. 2012. Strategy \& Competition Big Data: The Management Revolution. Harvard Business Review, 90(10), pp.60-68.

Ottman, A.J., Stafford, R.E. and Hartman, L.C., 2006. Avoiding Green Marketing Myopiaways to Improve Consumer Appeal for Environmentally Preferable Products. Environment, 49(5), pp.24-36.

Papadas, K., Avlonitis, J.G. and Carrigan, M., 2017. Green marketing orientation: Conceptualization, Scale Development and Validation. Journal of Business Research, 80, pp.236-246.

Peattie, K., 2001. Towards sustainability: the third age of green marketing. The Marketing Review, 2(2), pp.129-146.

Pistol, L, Epure, M. and Bucea-Manea- Ţoniş, R., 2016. WEB-Marketing Strategy for SMEs, Procedia of Economics and Business Administration, 1, pp.128-137.

Pistol, L. and Ţoniş (Bucea-Manea), R., 2017. Resource Productivity in a Circular Economy. In: s.n., 30th International Business-Information-Management-Association Conference, Vision 2020: Sustainable Economic Development, Innovation Management, and Global Growth. Madrid, Spain, n.d. s.l:s.n.

Pop, N.A. and Dabija, D.C., 2013. Development of an organic food mentality in Romania. In: A.R. Thomas, N.A. Pop and C. Brătianu, eds. 2013. The Changing Business Landscape of Romania: Lessons for and from Transition Economies. New York: Springer Publishing House, pp.45-60.

Power, D.J., 2014. Using 'Big Data'for analytics and decision support. Journal of Decision Systems, 23(2), pp.222-228.

Radnovic, B., Ilic, M. and Zivkovic, Z.D., 2012. Green marketing and sustainable development-experiences from Republic of Serbia. Journal of Economic Development, Environment and People, 1(3), pp.77-91.

Ratcliffe, W. and Coutler, C., 2015. Best practice: Green marketing. Warc Best Practice, pp.1-8.

Roberts, J.H., Kayande, U. and Stremersch, S., 2014. From academic research to marketing practice: Exploring the marketing science value chain. International Journal of Research in Marketing, 31(2), pp.127-140.

Sivarajah, U., Kamal, M.M., Irani, Z. and Weerakkody, V., 2017. Critical analysis of Big Data challenges and analytical methods. Journal of Business Research, 70, pp.263-286.

Song, M.L., Fisher, R., Wang, J.L. and Cui, L.B., 2018. Environmental performance evaluation with big data: Theories and methods. Annals of Operations Research, 270(12), pp.459-472. 
Şerban, M., Hurloiu, L.R., Ştefan, R.M. and Hurloiu, I.I., 2015. Situations referring to the organization, classification and management of economic data. Annals of Spiru Haret University. Economic Series, 15(3), pp.31-38.

Ştefan, R.M., Şerban, M., Hurloiu, I.I. and Rusu, B.F., 2016. Kernel Methods for Data Classification. International Conference Knowledge-Based Organization, 22(3), pp.572575).

WCED, 1987. Our Common Future. World Commission on Environment and Development. Oxford: Oxford University Press.

Wu, K.J., Liao, C.J., Tseng, M.L., Lim, M.K., Hu, J. and Tan, K., 2017. Toward sustainability: using big data to explore the decisive attributes of supply chain risks and uncertainties. Journal of Cleaner Production, 142, pp.663-676.

Wu, X.D., Zhu, X.Q., Wu, G.Q., Ding, W., 2014. Data Mining with Big Data. IEEE Transactions on Knowledge and Data Engineering, 26(1), pp.97-107

Zaman, G. and Gherasim, Z., 2010. Information Technology and communication (IT\&C) and Research and Development (R\&D), outstanding factors of the post-crisis economic recovery. Annals of Spiru Haret University. Economic Series, 1(3), pp.11-28. 